\title{
Interactive Listening and Speaking Teaching Based on Multimedia Assisted Instruction
}

\author{
Wei Wei \\ School of Foreign languages \\ Northwest Minzu University \\ Lanzhou, China \\ lsslv@126.com
}

\begin{abstract}
The purpose of this paper is to discuss the interactive modes with multimedia assisted instruction in English listening and speaking, in which good relationship between teachers and students and collaboration among students are of great importance. The English listening and speaking performance of students in the experimental group is significantly better than that in the control group. To conduct student-centered teaching mode, to formulate scientific and feasible teaching plans, and to create an interactive learning platform for students can be the strategies for realizing interactive mode of English listening and speaking under multime dia environment.
\end{abstract}

Keywords-interaction; listening and speaking; multimedia assisted instruction

\section{INTRODUCTION}

Listening is understanding, and speaking is expressing. The two are important communication skills. It is hard to separate in training and use. The training can be flexibly conducted in different stages and with different methods. The Requirements of College English Curriculum promulgated by the Ministry of Education pointed out that colleges and universities should cultivate students' comprehensive English application ability, especially listening and speaking abilities. In accordance with the conditions of the university and the students' English level, colleges and universities should explore and establish the teaching mode of listening and speaking with the aid of the multimedia. Listening and speaking training can be carried out via the LAN or the campus network [1].

There are some theories on language learning. Stephen Krashen put forward comprehensive input, which refers to input that slightly exceeds the current level of language learners. If " $\mathrm{i}$ " is a language learner's current foreign language proficiency level, then " $i+1$ " is the next step in the development process. Therefore, if the goal is to help language learners complete their tasks, comprehensive " $\mathrm{i}+1$ " must be provided to them [2].

Constructivism holds that the knowledge of the learners is acquired through the construction of meaning and obtaining of necessary information in a certain situation, with the help of others, such as the cooperation and communication between learners. The ideal learning environment should include four

This work was financially supported by Central Government Special Funds for Northwest Minzu University (Grant No. 31920130078) parts: situation, cooperation, communication, and meaning construction [3]. Nowadays, the development and application of multimedia and network technology provide the necessary technical support for the application of constructivist theory. Multimedia assisted instruction can integrate effectively into constructivism in the listening and speaking teaching process to provide an ideal teaching environment for autonomous learning. Vivid language materials, shown by means of sounds, images, words, animations and videos, create a real or nearly real language learning environment. Multimedia and network technology create good conditions for collaborative learning and communication beyond time and space limits. It helps students to construct English knowledge and skills, and produces a new learning way to meet the requirements of students' independent exploration, situation creation, multiple interactions, cooperative learning and resource sharing [4].

The studies on listening and speaking teaching through multimedia vary. Hwang et al [5] did a research on the learning process in game learning environment, and also took into account students' learning anxieties. Quasi experimental method was used to evaluate students' listening achievement, learning motivation and English anxiety. In addition, the learning behavior patterns of students with different anxiety levels were studied by stepwise sequential analysis. They found that the game method was conducive to students' listening achievement and motivation. In addition, the students with higher English anxiety level have better listening achievements than those with lower anxiety level. Hassani et al [6] proposed an intelligent language environment for language learning to improve the listening and speaking skills of non-native English learners. They integrated virtual environment into intelligent computer-aided language learning. They also designed a computational model to assess learners' proficiency and adjust their learning curve automatically. The results showed that in their three experiments, the number of correct answers increased by $14 \%$; the grammatical errors were reduced by $3 \%$; the duration of pronunciation was reduced by $16 \%$; and the proficiency of the learners was increased by $11 \%$.

\section{METHODS}

This research adopts the methods of experiment, interview and classroom observation to analyze the feasibility and effectiveness of the interactive teaching method. The subjects 
of this study come from Northwest Minzu University, Gansu Province. The English level of these students is medium. The two classes are randomly assigned to be the experimental group and the control group. There are 50 students in the experimental group (EG) and 45 in the control group (CG). With the experimental method as the core and the interview and classroom observation methods as supplement, different teaching methods are carried out in the experiment class and the control class. Classroom observation and interview are interspersed in the teaching process, and the final results are compared as the main research results.

The specific schemes are as follows: (1) Choose one term as the experimental period. (2) In the experimental class, the multimedia interactive mode of English teaching is implemented, and the same normal teaching method as before is performed in the control class. (3) Observe the experimental class in the teaching process and conduct interviews with the students. (4) Make a comparative analysis of the final exam results, draw the conclusion of the study, and put forward constructive strategies for the reform of Multimedia Interactive Teaching.

This study will address the following questions: (1) What are the interactive modes with multimedia assisted instruction (MAI) in English listening and speaking? (2) What is the effect of application of interaction with MAI to English listening and speaking? (3) What strategies can be taken to realize interactive mode of English listening and speaking under multimedia environment?

\section{RESULTS AND DISCUSSIONS}

\section{A. Interactive modes with MAI}

- Good relationship between teachers and students. According to social constructivism, a feature of facilitator's role is that teachers and students are also involved in learning from each other [7]. This means that learning experience is subjective and objective, and requires teachers' culture, values and background to become an important part of interaction between students and tasks in the process of meaning formation. Students compare their views about truth with teachers and other students, and get some new views about truth from social testing [8]. Tasks or problems are the interface between teachers and students. This produces a dynamic interaction between tasks, teachers and students. This means that teachers and students should develop their understanding of each other's views, and then look at their own beliefs, standards and values both subjectively and objectively [9]. Some studies consider the importance of guidance in the learning process. Social constructivism mode emphasizes the importance of teacher-student relationship in the process of learning. Some methods of interactive learning can include interactive teaching, peer collaboration, cognitive apprenticeship, problem-based teaching, network tasks, anchored teaching, and other methods of learning with others.
- Collaboration among students. Students who have different skills and backgrounds should cooperate in tasks and discussions to achieve a common understanding of the knowledge in certain aspects. Some social constructivists also emphasize the need for cooperation between students, which is obviously contradictive to the traditional competitive methods [10]. Vygotsky put forward the concept of the zone of proximal development which is of great importance to peer cooperation [11]. It is defined as the distance between the actual level of development in an independent solution and the potential development level guided by an adult or with a more capable partner. When students learn new knowledge with peers, a collective knowledge construction will be built. Students' zone of proximal development can be evaluated through interaction with peers since students can get the chance of imitation, which is not enough for independent solution. According to Vygotsky, a student cannot imitate anything, but it is likely that the student can imitate only what exists within the zone of proximal development and get skills by understanding.

\section{B. The effect of application of interaction with MAI}

The results of the experiment show that the majority of the students in the experimental class believe that the multimedia interactive English listening and speaking teaching had a significant effect on improving English learning interest and high English performance. Through interviews, most students believe that the effect of the implementation of this model is not only reflected in listening and speaking, but also in reading and writing. Students' basic English skills have been greatly improved. In the experimental class, students' learning enthusiasm is obviously higher, and they all want to integrate themselves into classroom teaching.

In EG English listening and speaking class, students are instructed with the interactive mode under multimedia environment. The traditional teaching methods are employed in the CG English listening and speaking class. The mode of manmachine conversation is adopted in the English listening and speaking tests, and the tests are conducted in the computer room. Three teachers independently give the mark to each student in the pretest and posttest. The total score is 15, and the average score from three teachers is calculated.

Table 1 shows independent T-test results of scores in the pretest and posttest for EG and CG. In the pretest, the mean score of EG is 9.390 with its standard deviation (SD) 1.480, and the mean score of CG is 9.489 with its standard deviation 1.788. The mean score and standard deviation of CG are higher than those of EG, but are not significantly higher than those of EG because $\mathrm{p}$-value is higher than $0.05(\mathrm{t}=-0.308)$. In the posttest, the mean score of EG is 11.823 with its standard deviation 1.382, and the mean score of CG is 10.113 with its standard deviation 1.797. The mean score and standard deviation of EG are significantly higher than those of CG because p-value is smaller than $0.05(\mathrm{t}=7.891)$.

The results of paired T-test show that while the mean score of the posttest is significantly higher than that of the pretest in 
EG ( $p<0.05$ ), the mean score of the posttest is not significantly higher than that of the pretest in CG ( $p>0.05)$.

TABLE I. T-TEST RESULTS OF SCORES

\begin{tabular}{|c|c|c|c|c|c|c|}
\hline Tests & Groups & Number & Mean & SD & t & p \\
\hline \multirow{2}{*}{ pretest } & EG & 50 & 9.390 & 1.480 & \multirow{2}{*}{-0.308} & \multirow{2}{*}{0.663} \\
\cline { 2 - 6 } & CG & 45 & 9.489 & 1.788 & & \\
\hline \multirow{2}{*}{ posttest } & EG & 50 & 11.823 & 1.382 & \multirow{2}{*}{7.891} & \multirow{2}{*}{0.025} \\
\cline { 2 - 5 } & CG & 45 & 10.113 & 1.797 & & \\
\hline
\end{tabular}

According to the results of the study, the author believes that the improvement of students' English achievement comes from the longing for English classes. For the students with weak foundation, the traditional teaching mode is dull and boring. It is difficult for them to integrate into the classroom. The multimedia interactive mode has formally changed the difficulty of students' English learning, so that they can regain the hope of learning English well.

First of all, multimedia interactive teaching mode has realized the diversification of teaching contents. Under this model, the teaching contents are chosen according to the principle of stimulating the students' interest in learning, and the teaching contents are not confined to a textbook or a copy of material. In English listening and speaking teaching, students are taught in accordance with their aptitude. The real language materials make the teaching environment close to the nature to the maximum extent. This has greatly stimulated students' interest in learning and rebuilt confidence for students to learn English well.

Secondly, the multimedia interactive teaching mode has realized the three-dimensional form of teaching organization. This model makes teaching become the form of 'teachers' guidance in the classroom + students' interactive learning + students' practice after class”, which makes teaching become an activity between teachers and students, and collaboration among students. Teachers make full use of multimedia and network technology to carry out individualized language teaching.

Finally, the multimedia interactive teaching mode has realized the integration of. Under this model, the coexistence and complementary advantages of multiple teaching methods, namely autonomous learning model, cooperative learning model, digital and networked learning model, are implemented.

\section{Strategies for realizing interactive mode of English listening and speaking under multimedia environment}

Firstly, student-centered teaching mode can be conducted in the classroom. The most important feature of multimedia teaching is interaction. In order to realize interaction, teachers should focus on the students' autonomous learning. Students' English achievement can be improved through the interaction among them. This interactive model shows the interaction between teachers and students, students and students, students and teaching content, students and the multimedia, and emphasizes individualized teaching and autonomous learning. Therefore, the traditional mode of teachers' classroom teaching and students' passive learning can be transformed into that of teachers' guidance and students' autonomous learning. Both teachers and students change their roles. Teachers are responsible for curriculum design, management and evaluation of teaching effectiveness, acting as demonstrators and consultants in the whole teaching process. Students act as the implementers of autonomous learning, and become participants in the teaching process, explorers of knowledge and practitioners of skills.

Secondly, scientific and feasible teaching plans can be formulated. Making a good teaching plan is the key to the realization of multimedia interactive teaching. The teaching plan should reflect the diversity of teaching contents, the diversity of teaching forms and the diversification of teaching methods.

Thirdly, an interactive learning platform for students can be created under the multimedia environment. A good interactive learning platform includes classroom, class interaction and multimedia, and also teachers' teaching effect detection platform. In the way of classroom guidance, the students' enthusiasm is mobilized so that students can realize their own practice. Then, through the interaction on the multimedia after class, listening and speaking can be effectively combined.

\section{SUMMARY}

In the English listening and speaking teaching classes, teachers should follow the language teaching principle of "input - internalization - output", make full use of the equipment of multimedia, and use materials with the aid of multimedia for the ideal input of the language. Teacher can also carry out hierarchical teaching according to the individual differences of the students to realize the comprehensive language input in the real sense. At the same time, teachers should actively create a harmonious and relaxed learning atmosphere, mobilize students' learning enthusiasm, improve their self-confidence, and weaken their emotional anxiety. An environment created between students and teachers, students and students, can promote the effective language output of students.

The purpose of developing interactive mode of Multimedia English listening and speaking is to achieve the goal of improving students' comprehensive English quality. The research shows that the interactive mode teaching of English listening and speaking under multimedia environment can effectively and quickly improve students' English comprehensive level. The reform of the teaching mode is not a simple way to change the teaching mode, but the realization of the hierarchical, individualized, autonomous, and diversified mode. The most important thing is the change of the role of teachers and students, the scientific compilation of the teaching plan and the establishment of an interactive learning platform. With these changes, autonomous learning, collaborative learning and networked learning can be introduced into teaching in order to mobilize students' learning enthusiasm to ultimately improve students' overall English level. 


\section{ACKNOWLEDGMENT}

I would like to give my sincere gratitude to Prof. Zhang Hanbin, my colleague who, with extraordinary patience and consistent encouragement, gave me great help by providing me with necessary materials, advice of great value and inspiration of new ideas.

\section{REFERENCES}

[1] The Requirements of College English Curriculum, the Ministry of Education, Shanghai: Shanghai Foreign Language Education Press, 2008.

[2] S. Krashen, The Input Hypothesis: Issues and Implication, London: Longman, 1985.

[3] S. Tobias and T. M. Duffy, Constructivist instruction: Success or failure?, New York: Taylor \& Francis, 2009.

[4] A. Sarkar, "Constructivist Design for Interactive Machine Learning," Proceedings of the 2016 CHI Conference Extended Abstracts on Hu man Factors in Computing Systems, New York, USA: ACM, pp.1467-1475, 2016.
[5] G. J. Hwang, T. C. Hsu, C. L. Lai, and C. J. Hsueh, "Interaction of problem-based gaming and learning anxiety in language students' English listening performance and progressive behavioral patterns," Computers \& Education, vol. 106, pp.26-42, 2017.

[6] K. Hassani, A. Nahvi, and A. Ahmadi, "Design and implementation of an intelligent virtual environment for improving speaking and listening skills,” Interactive Learn ing Environments, vol. 24(1), pp.252-271, 2016.

[7] D. G. Holt and C. Willard-Holt, "Let's Get Real ${ }^{\mathrm{TM}}$ : Students Solving Authentic Corporate Problems," Phi Delta Kappan. vol. 82 (3), pp.243246, November 2000.

[8] A. Kukla, Social constructivism and the philosophy of science. Routledge, 2013.

[9] Kim, "The effects of a constructivist teaching approach on student academic achievement, self-concept, and learning strategies," Asia Pacific Education Review, vol. 6 (1), pp. 7-19, 2005.

[10] S. P. McCaleb, Building communities of learners: A collaboration among teachers, students, families, and community, Routledge, 2013.

[11] S. Karim, "Vygotsky' zone of proximal development: instructional implication and teachers' professional development," English Language Learning, vol. 3, pp.237-257, 2010. 